\title{
A QUESTÃO DE GÊNERO COMO DIVERSIDADE CULTURAL NAS EMPRESAS: IMPACTOS DAS MULHERES E LGBT'S NA GESTÃO DO CONHECIMENTO
}

THE GENDER ISSUE AS CULTURAL DIVERSITY IN BUSINESS: IMPACTS OF WOMEN AND LGBT'S IN KNOWLEDGE MANAGEMENT

\author{
B. R. P. dos SANTOS ${ }^{1, *}$, S. L. C. OTTONICAR ${ }^{2}$, L. P. P. de SOUZA $^{3}$ e I. P. M. \\ DAMIAN 4
}

\begin{abstract}
${ }^{1}$ Universidade Estadual Paulista, Faculdade de Filosofia e Ciências, Programa de Pós-Graduação em Ciência da Informação, Brasil

2 Universidade Estadual Paulista, Faculdade de Filosofia e Ciências, Programa de Pós-Graduação em Ciência da Informação, Brasil

3 Universidade Estadual Paulista, Faculdade de Filosofia e Ciências, Programa de Pós-Graduação em Ciência da Informação, Brasil

4 Universidade de São Paulo, Faculdade de Filosofia, Ciências e Letras, Departamento de Biblioteconomia e Ciências da Informação, Brasil
\end{abstract}

\section{A R T I C L E I N F O}

Article history:

Received 2018-07-02

Accepted 2018-10-17

Available online 2018-10-31

*Autor correspondente:

E-mail:pedagogomarcio@gmail.com
Palavras-chave: Diversidade cultural. Gestão do conhecimento. LGBT. Mulher. Interdisciplinaridade

Keywords: Cultural diversity. Knowledge management. LGBT. Woman. Interdisciplinarity.

RESUMO. As organizações contemporâneas necessitam de informação para transformá-las em conhecimento, pois este faz parte do processo de aprendizagem. Além disto, a quantidade de saberes produzidos pelos funcionários demanda uma gestão específica e estratégica, a fim de armazenar o conhecimento para recuperação futura. Essa gestão depende da valorização da informação e do conhecimento como insumos para tomada de decisão, portanto, utiliza de sua cultura organizacional para implementar a gestão do conhecimento. Portanto, a pesquisa faz os seguintes questionamentos: a diversidade cultural pode ser considerada um fator crítico de sucesso da gestão do conhecimento? Como a diversidade cultural pode contribuir para a implantação da gestão do conhecimento nas organizações? O objetivo é refletir sobre a diversidade cultural na organização como fator crítico de sucesso na gestão do conhecimento. Nesta pesquisa, a diversidade cultural das 
organizações enfoca as questões de gênero no contexto do trabalho. Deste modo, envolve as mulheres e os homossexuais de modo geral. Discute-se ainda como a tecnologia pode criar um espaço para a expressão da diversidade cultural. A metodologia envolve uma revisão de literatura com enfoque interdisciplinar, utilizando obras das seguintes áreas: Administração, Ciência da Informação, Ciências Sociais e Economia. Os resultados $e$ as discussões apontam que embora a questão do gênero esteja cada vez mais presente na sociedade e nas organizações, ainda são escassos os trabalhos relacionando gênero e gestão do conhecimento. Como considerações finais, ressalta-se que é premente a necessidade de estudos enfocando a temática já referida, visando a construção de organizações e sociedades mais inclusivas.

ABSTRACT. Contemporary organizations need information to turn them into knowledge, as this is part of the learning process. In addition, the amount of knowledge produced by employees demands specific and strategic management in order to store the knowledge for future recovery. This management depends on the valorization of information and knowledge as inputs for decision making, therefore, uses its organizational culture to implement knowledge management. Therefore, the research asks the following questions: can cultural diversity be considered a critical success factor of knowledge management? How can cultural diversity contribute to the implementation of knowledge management in organizations? The goal is to reflect on cultural diversity in the organization as a critical success factor in knowledge management. In this research, the cultural diversity of organizations focuses on gender issues in the context of work. In this way, it involves women and homosexuals in general. It is also discussed how technology can create a space for the expression of cultural diversity. The methodology involves a literature review with an interdisciplinary approach, using works from the following areas: Administration, Information Science, Social Sciences and Economics. The results and discussions point out that, although the issue of gender is increasingly present in society and in organizations, there is still little work relating gender and knowledge management. As final considerations, it is emphasized that the need for studies focusing on the aforementioned subject is urgent, aiming at the construction of more inclusive organizations and societies.

\section{Introdução}

A gestão do conhecimento (GC) é um processo fundamental para as organizações contemporâneas, pois possibilita que os colaboradores explicitem seu conhecimento e o armazenem para serem recuperados posteriormente. Desse modo, evita a repetição dos processos provenientes das atividades dos departamentos e dos profissionais. As pesquisas apontam que tal tipo de gestão influencia a competitividade organizacional (SANTOS, YAFUSHI, 2015; VALENTIM; MOLINA, 2013). Cada conhecimento é produzido a partir de informação interpretada pelos indivíduos, portanto essa pesquisa defende que a criação de conhecimento ocorre por meio do ser humano.

Os seres humanos possuem valores, crenças, rituais, história, ou seja, são seres guiados desde o nascimento pela cultura. A organização é formada pelas pessoas que a compõem, por isso a cultura neste contexto foi denominada de cultura organizacional. Assim, a explicitação do conhecimento envolve questões cognitivas, comportamentais, sociais e ocorre dentro de um contexto. Defende-se que não existe uma única maneira de implantar a GC, pois cada localidade e organização possuem características culturais que a diferem das demais. 
Assim, os problemas da presente pesquisa são: a diversidade cultural pode ser considerada um fator crítico de sucesso da GC? Como a diversidade cultural pode contribuir para a implantação da GC nas organizações? O objetivo é refletir sobre a diversidade da cultura organizacional como fator crítico de sucesso na implantação do processo de GC nas organizações contemporâneas. Assim, nesse trabalho, a diversidade cultural das organizações possui como foco as questões de gênero no contexto do trabalho e envolve as mulheres e os grupos LGBT. Discute-se ainda o papel imprescindível da tecnologia para a formalização e difusão de conhecimentos bem como a possibilidade da criação de espaços virtuais democráticos que permitam um debate igualitário, considerando as questões culturais e de gênero, uma ágora virtual, como define Lévy (1998).

Algumas organizações ainda têm dificuldades para lidar com a questão de gênero, pois muitas ainda estão apegadas as estruturas sociais tradicionais, regidas pelo patriarcado. As mulheres ainda ganham menos que os homens na mesma posição e grupos LGBT ainda são contratados em pequena quantidade.

Tanto a literatura sobre a Gestão quanto sobre a Ciência da Informação apontam os fatores críticos de sucesso da GC como treinamento de funcionários, envolvimento dos trabalhadores, trabalho em equipe, capacitação de funcionários, liderança da alta gerência e comprometimento, competência em informação, entre outros (FURLANETO; OLIVEIRA, 2008).

Além desses fatores, defende-se que a diversidade cultural dos funcionários também influencia no processo de implantação da GC, algo muito presente principalmente no Brasil, que é um país composto por diferentes povos e etnias. Desse ponto de vista, a gestão da diversidade cultural passa a ser algo necessário nas organizações brasileiras, porém poucos trabalhos na área tratam do assunto.

$\mathrm{Na}$ área da Ciência da Informação existem diversas pesquisas que tratam da cultura e do comportamento informacional. Esses trabalhos demonstram que são as pessoas que qualificam a informação. Sendo assim, o desenvolvimento desse tipo de estudo é fundamental para a área (VALENTIM, 2014). Além da relevância da cultura para os estudos sobre comportamento informacional, é fundamental considerar o papel desta no processo de GC. Os indivíduos produzem conhecimento na organização e são seres compostos por seus valores, ideologias, tabus, comportamento e aparência física. Todos esses elementos compõem a cultura, portanto não se pode falar em construção de conhecimento sem abordar o contexto que as pessoas vivem.

O trabalho se embasa na perspectiva discutida por Semprini e Pelegrin (1999), na qual grupos sociais que partilham valores, demandas e problemas em comum podem ser considerados como culturas. Discute-se também a visão de Hofstede, Pedersen e Hofstede (2002) do gênero como um valor fundamental para a caracterização da cultura e o papel 
dessa cultura na relação do indivíduo com a informação e o trabalho, como destaca Wilson (1997). Ainda que se reconheça o valor da cultura organizacional na GC, é enfocado no presente trabalho como os aspectos culturais pessoais trazidos pelos sujeitos organizacionais podem ser transformados em valor para a organização.

A metodologia envolve uma pesquisa bibliográfica sobre LGBT, mulher e GC em livros, periódicos e base de dados (GIL, 2009; MARCONI, LAKATOS, 2017) tanto da área da Ciência da Informação quanto da Gestão. Esse tipo de pesquisa se adéqua principalmente aos temas inovadores e interdisciplinares por trazer uma nova reflexão para ambas às áreas e novas possibilidades de aplicação prática dos conceitos.

\section{Desenvolvimento}

\section{Diversidade Cultural: conceitos e fundamentos}

Os conceitos de diversidade cultural estão atrelados à formação, composição e interrelações do mundo, que atualmente é o espelho e a própria identidade da diversidade cultural. Essas inter-relações entre as culturas de diversos grupos são resultados da globalização que ocorre por meio do conjunto de interações entre as diversas culturas de diferentes países que constituem o globo.

De acordo com a UNESCO (2005), a diversidade cultural está diretamente relacionada ao contexto múltiplo de expressão cultural de grupos sociais e sociedade. Essa diversidade tem o poder de enriquecer o patrimônio cultural da humanidade. Além disso, ainda segundo a UNESCO (2005), é importante defender a diversidade cultural, pois um dos seus objetivos se pauta pela busca da paz entre os povos, e claramente, da diminuição dos conflitos humanos.

Entretanto, diferentes culturas e diferentes formas de expressão provocam conflitos e intolerância em níveis micro e macro social, onde o ódio e a falta de respeito com o próximo encontra-se cada vez mais visível, como se vê todos os dias nos noticiários. Nesse sentido, Carvalho (2010) caracteriza e afirma que os fundamentos e a missão da diversidade cultural é o combate aos preconceitos ligados ao gênero, raça, religião, deficiências, entre outros. No âmbito do ano de 2017 podem-se incrementar as seguintes características: política, classe social e orientação sexual, não porque são características novas no mundo, mas porque estão incitando preconceitos cada vez maiores nos ambientes da sociedade. Em síntese, Cox (1993) afirma que diversidade cultural é uma representação de pessoas e grupos com características culturais distintas, em qualquer ambiente social. Ademais, para o autor, essa representação se divide entre os grupos de minorias e grupos de maioria, que podem ser mais bem especificados em um ambiente organizacional.

\section{A força da diversidade cultural no Brasil}


Ainda que se possa pensar em diversidade cultural em termos de pessoas de nacionalidades distintas, que de alguma forma fazem parte de um mesmo grupo social, pode-se tratar também de diversidade cultural em termos da riqueza de tradições distintas existentes entre os próprios brasileiros. Existe uma multiplicidade de perspectivas culturais no Brasil, devido à miscigenação, à imigração e à diversidade sexual. Dentre essas subculturas há algumas cujos membros são, na prática, colocados à margem do contexto social, sofrendo um tratamento desigual em vários âmbitos da vida.

\section{Cultura e Gênero}

Além da diversidade regional no âmbito da cultura, existe outra questão relevante, que tem ganhado destaque no âmbito empresarial e na sociedade, a questão do gênero. $A$ este respeito, é relevante tratar de aspectos culturais relativos a dois grupos que, ao longo da história, sofreram e têm sofrido discriminação não só no contexto de trabalho, como no âmbito da sociedade em geral: as mulheres e os membros da comunidade dos Gays, Lésbicas, Bissexuais, Travestis, Transexuais e Transgêneros (LGBT).

Hofstede, Pedersen e Hofstede (2002) descrevem as cinco dimensões de valor das culturas nacionais: identidade, sendo a tendência para o coletivismo ou individualismo; hierarquia, ou grau de igualdade ou desigualdade na distribuição de poder; gênero, ou a orientação para valores masculinos versus femininos; verdade, ou grau de aceitação da incerteza; virtude, ou orientação a longo ou curto prazo na vida. Para o autor supracitado, o gênero na cultura tem relação com o nível de competitividade e agressividade, identificados com o aspecto masculino, versus posturas mais igualitárias na distribuição de poder, que prezam o cuidar do outro, o comprometimento com valores humanísticos, identificados com o aspecto feminino.

Porém, poder-se-ia questionar se as mulheres e indivíduos LGBT, justamente por abrangerem pessoas de distintas nacionalidades e tradições, poderiam realmente se configurar como culturas distintas. Semprini (1999) alega que o multiculturalismo pode ser visto por duas perspectivas: uma é a perspectiva política, onde minorias buscam obter direitos sociais e políticos no âmbito dos estados nacionais, tendo algum nível de homogeneidade étnica ou nacional. Outra é a perspectiva dita cultural, na qual não há necessariamente homogeneidade étnica ou nacional, mas movimentos sociais que unem indivíduos por meio de valores comuns, um sentimento de identidade e/ou uma situação de marginalização. 


\section{Os desafios das mulheres}

Dentre todos os desafios enfrentados pelas mulheres, e que estão também presentes no âmbito empresarial, pode-se destacar um em especial, que denota a marginalização da mulher no mercado de trabalho: a disparidade salarial. Lips (2012) afirma que o fato de as mulheres ganharem menos que os homens é uma realidade mundial e que essa disparidade se dá mesmo em situações em que o nível educacional e o investimento na carreira são iguais aos dos colegas do sexo masculino. A autora explica ainda que a maior parte dos trabalhos de meio período, com menor pagamento, é ocupada por mulheres, mas que é preciso considerar as pressões sociais que levam as mulheres a optarem por esse tipo de trabalho.

Para Atkinson (2016) a maternidade é uma condição que precisa ser tratada com atenção no âmbito empresarial, que pressiona a escolha de trabalhos de meio período, e resulta até mesmo na perda de promoções, levando as mulheres a ganharem menos por vários anos após o nascimento de seus bebês. Dentre as soluções propostas pela autora estão: permitir licenças aos pais para cuidar dos filhos; subsidiar o pagamento de creches; permitir o trabalho em casa ou permitir levar os bebês para o trabalho; aumentar o salário de serviços com baixos salários majoritariamente desempenhados por mulheres, como cuidar de pessoas e efetuar limpeza.

\section{A comunidade LGBT}

Outro grupo que enfrenta a marginalização e tem lutado pelo seu reconhecimento perante a sociedade em geral e no mercado de trabalho é a comunidade LGBT. Davi (2011) afirma que o interesse de historiadores e demais pesquisadores pela cultura LGBT é um fenômeno relativamente recente, visto que ela tinha sido até então reprimida, todavia sempre encontrando maneiras sutis de burlar o sistema e se expressar meio da música, do teatro, da literatura e da sátira dos signos tradicionais de poder.

É interessante considerar que a construção de uma cultura LGBT tem a ver com a formação de uma identidade e a reivindicação de um espaço na sociedade para indivíduos que eram anteriormente vistos como párias sociais. Irvine (1998) afirma que a ideia de uma cultura LGBT surgiu para garantir reconhecimento e respeito ao homossexual perante a sociedade, dando a ele um sentido de membro de uma comunidade maior, não simplesmente um ser isolado que sofre de um desvio sexual, como era antes encarado.

A elaboração de políticas específicas para integrar colaboradores homossexuais têm sido um importante passo dado pelas empresas em relação à aceitação da diversidade. 
Siqueira (2015) afirma que em 2013 a Câmara Internacional de Comércio dos Gays e Lésbicas criou uma lista das 10 empresas, todas estrangeiras, gay friendly. Para o autor supracitado, O termo gay friendly é definido como locais, pessoas, instituições e políticas que contribuem para que os indivíduos LGBT sejam respeitados.

É importante ressaltar que as empresas brasileiras também estão preocupadas com a diversidade de modo geral, abordando também a diversidade sexual em maior ou menor grau. Dentre as empresas nacionais que têm alguma forma de política de suporte aos membros da comunidade LGBT, o autor menciona: Itaú Unibanco, Banco do Brasil, Gol Linhas Aéreas, e outras. Ressalta-se que algumas organizações têm se conscientizado da importância de refletir a diversidade cultural que existe na sociedade, embora ainda haja muitas barreiras e preconceitos a serem vencidos. É relevante que a empresa tenha capacidade de trabalhar as múltiplas perspectivas culturais em âmbito interno, em relação aos seus colaboradores, para que esteja apta também a atender a um público consumidor cada vez mais heterogêneo.

\section{Gestão do Conhecimento e os Fatores Críticos de Sucesso}

A informação e o conhecimento participam do desenvolvimento da sociedade de maneira geral, assim a partir do início do século XX há grandes esforços e estudos sobre o tema, principalmente em âmbito da gestão das organizações (JANUZZI, 2016). Tanto a área da Ciência da Informação quanto a Gestão reconhecem a GC como fator de influência na vantagem competitiva organizacional. Independentemente do tamanho da organização, conforme explicam Trindade et al (2017), as pequenas e médias empresas participam de maneira ativa na economia internacional, assim ao gerir o conhecimento estas instituições alcançam competitividade organizacional. A GC está focada no conhecimento criado pelas pessoas que necessita de uma gestão sistematizada para obter competitividade (OLIVEIRA, OLIVEIRA, LIMA, 2016).

Assim, as organizações reconhecem a informação e o conhecimento como recurso para as atividades, uma vez que atua diretamente na vantagem competitiva, no contexto das organizações públicas tem como missão o desenvolvimento do país e para as Organizações sem fins lucrativos e não governamentais na melhoria dos seus serviços oferecidos. Assim, o conhecimento é visto como um recurso gerenciável e os esforços profissionais se baseiam nessa premissa. Várias abordagens na teoria norteiam a gestão do conhecimento organizacional como a aprendizagem individual, organizacional e o capital intelectual (JANUZZI, 2016).

Valentim (2014, p. 4, grifo nosso) explica que este processo: 


\begin{abstract}
A gestão do conhecimento é um conjunto de atividades que visa trabalhar a cultura organizacional/informacional e a comunicação organizacional/informacional em ambientes organizacionais, no intuito de propiciar um ambiente positivo em relação à criação/geração, aquisição/apreensão, compartilhamento/socialização e uso/utilização de conhecimento, bem como mapear os fluxos informais (redes) existentes nesses espaços, com o objetivo de formalizá-los, na medida do possível, a fim de transformar o conhecimento gerado pelos indivíduos (tácito) em informação (explícito), de modo a subsidiar a geração de ideias, a solução de problemas e o processo decisório em âmbito organizacional.
\end{abstract}

A GC conecta o saber explícito e o tácito com a finalidade de criar valor. Nessa interrelação aparecem as competências, a cultura de compartilhamento, ampliação das redes de conhecimento, a valorização dos ativos intelectuais, bem como o uso em cada ambiente (MENEZES et al., 2017). Toda essa estrutura está relacionada com o ser humano, é ele o principal elemento dessa gestão juntamente com a tecnologia de informação e comunicação (TICs).

A GC trabalha com os fluxos informais da organização, estes fluxos não são sistematizados, como por exemplo, a cultura, a comunicação, o comportamento, a aprendizagem, valores e práticas (VALENTIM, 2014). Na área da Ciência da Informação existem divergências a respeito do tema, uma corrente defende que esta gestão contribui com o desenvolvimento da organização e a outra acredita que ela não existe. Januzzi, Falsarella, Sugahara (2016) complementa Valentim (2014) que os autores que criticam a viabilidade dessa gestão se sustentam na crítica de que ela advém da experiência da pessoa, da apropriação de informação interpessoal, no acesso a informação visando responder a necessidade de informação.

Valentim (2014) explica que essa corrente teórica compreende a GC como "gestão da mente humana", porém a primeira corrente teórica não a compreende desta maneira. Assim há uma divergência, inclusive, na compreensão de ambos os pontos de vista.

A GC, ao considerar os valores e a cultura dos indivíduos que atuam na organização contribui para sua implementação e manutenção. Portanto, as pesquisas de GC têm demonstrado refletir a respeito da cultura organizacional (BRAQUEHAIS et al, 2017). Complementando, Braquehais et al, 2017, Januzzi et al. (2016, p. 107) enfatiza que:

[...] Sendo discriminável (informação como coisa) e fazendo sentido (informação como conhecimento), a informação pode ser percebida e assimilada pelo receptor, cuja interpretação (construção do entendimento) terá como base o seu conhecimento prévio (crenças, experiências etc.) para a criação de novos conhecimentos (processos cognitivos).

A cultura do conhecimento precisa ser construída nas organizações, devendo ser mobilizado pelo entendimento da estrutura de poder existente. Para tanto, os gestores devem verificar a relação desta cultura com a GC. Com isso, emerge a cultura de 
valorização do conhecimento compartilhado, que se torna elemento fundamental para a inteligência competitiva (OLIVEIRA; OLIVEIRA; LIMA, 2016).

\subsection{A Tecnologia na Gestão do Conhecimento}

A tecnologia tem importante papel na explicitação do conhecimento pessoal proveniente da experiência, ou tácito, possibilitando que este conhecimento possa ser difundido mais amplamente na organização. Para Pérez-Montoro-Gutiérrez (2008), após se identificar os conhecimentos necessários ao sucesso da organização, identificar os indivíduos detentores desses conhecimentos e discutir maneiras de representar os conhecimentos, deve-se considerar as ferramentas tecnológicas para apoiar os processos de GC. O autor divide essas ferramentas em soluções parciais, que cobrem apenas alguns requisitos da GC de modo autônomo e isolado, e soluções integradoras, que apoiam a GC de modo global, intensificando os fluxos de conhecimentos explícitos e tácitos.

Ainda segundo o autor supracitado, dentre as soluções parciais se encontram os sistemas gerenciadores de bases de dados e ferramentas de data mining, que se prestam para evidenciar determinados padrões em enormes volumes de dados; dentre as soluções integradoras, é mencionada a intranet, uma rede computacional interna da organização para produção e compartilhamento de conteúdos. Marchand, Kettinger e Rollins (2001) afirmam que o sucesso da organização depende do uso eficaz da informação, atingido por meio de uma sólida infraestrutura de tecnologia da informação ( $\mathrm{TI})$, de processos de gestão da informação e da adoção de comportamentos adequados dos sujeitos organizacionais em relação à aquisição, compartilhamento e uso da informação.

A wiki pode ser considerada outra solução integradora. Souza e Ferrari (2015) descrevem o uso da wiki, um site cujo conteúdo é criado colaborativamente, para apoiar a GC em projetos de software, atividade que faz intenso uso de recursos cognitivos. Os autores salientam que a wiki permite a constante reavaliação dos conteúdos e sua exclusão, em caso de obsolescência. Esse recurso tecnológico pode ser utilizado em organizações de quaisquer ramos de atividades.

\section{Método}

O presente trabalho caracteriza-se como uma pesquisa exploratória, de cunho bibliográfico e de abordagem quali-quantitativa. É definida como exploratória, pois busca o estudo para compreensão do seu objeto de pesquisa e dos aspectos relacionados a ele, segundo Gil (2009). 
A pesquisa se baseia na cientometria para avaliar a produção científica sobre a relação do gênero com a GC, por meio de pesquisas realizadas em bases de dados nacionais e internacionais. As bases de dados analisadas foram: Library and Information Science Abstracts (LISA) e SCOPUS, Base de Dados Referenciais de Artigos de Periódicos em Ciência da Informação (BRAPCI), bem como a coleção brasileira da base SCIELO. Em todas as bases de dados foi delimitado um período de dez anos, compreendido entre 2006 a 2017. Nas duas bases internacionais, a busca se deu por termos em inglês, enquanto que nas nacionais, foram utilizados termos em português. $O$ filtro de busca restringiu a pesquisa ao título dos artigos.

A análise das bases nacionais foi importante para verificar como está o nível de produção brasileira sobre o tema, enquanto que a análise em bases internacionais dá margem para uma comparação da produção científica sobre o tema abordado em âmbitos nacional e internacional, o que propicia um fortalecimento da relevância do assunto.

\section{Resultados e Discussões}

Primeiramente, pesquisou-se, nas bases de dados brasileiras, sobre as palavraschave: gestão do conhecimento e LGBT; gestão do conhecimento e mulher; gestão do conhecimento e gênero. Pesquisaram-se artigos nas bases internacionais usando os termos: knowledge management and LGBT; knowledge management and woman; knowledge management and gender. Em todos os casos utilizaram-se aspas duplas, para que fossem recuperados artigos que contivessem exatamente os termos buscados. $O$ filtro de busca se restringiu aos títulos dos artigos.

Tabela 1: Produção Científica brasileira

\begin{tabular}{|c|c|c|}
\hline \multirow[t]{2}{*}{ Termos pesquisados } & \multicolumn{2}{|c|}{ Base de dados 2006-2017 } \\
\hline & SCIELO & BRAPCI \\
\hline $\begin{array}{l}\text { "Gestão do conhecimento" and } \\
\text { "LGBT" }\end{array}$ & 0 & 0 \\
\hline $\begin{array}{l}\text { "Gestão do conhecimento" and } \\
\text { "mulher" }\end{array}$ & 0 & 1 \\
\hline $\begin{array}{l}\text { "Gestão do conhecimento" and } \\
\text { "gênero" }\end{array}$ & 0 & 3 \\
\hline Total & 0 & 4 \\
\hline
\end{tabular}

Fonte: Dados da Pesquisa, 2017. 
A base de dados BRAPCI apontou para um total de 4 artigos. A busca pelos termos 'gestão do conhecimento' e 'mulher' retornou um artigo, enquanto que 'gestão do conhecimento' e 'gênero' retornou três resultados. Deve-se ressaltar que a pesquisa pelos termos 'gestão do conhecimento' e 'LGBT' retornou zero artigos. Na base SCIELO, analisando a coleção brasileira, não foi encontrado nenhum artigo que relacionasse a questão de gênero com a GC.

Tabela 2: Produção Científica internacional

\begin{tabular}{ccc}
\hline Termos pesquisados & Base de dados 2006-2017 \\
\hline Knowledge management and LGBT & SCOPUS & LISA \\
\hline Knowledge management and woman & 2 & 0 \\
\hline Knowledge management and gender & 3 & 0 \\
\hline Total & 5 & 0 \\
\hline
\end{tabular}

Fonte: Dados da Pesquisa - 2017.

$\mathrm{Na}$ base SCOPUS encontraram-se apenas cinco trabalhos que relacionassem questões de gênero e a GC, que podem contribuir no desenvolvimento da argumentação dos resultados. Salienta-se que a busca pelos termos 'knowledge management' (gestão do conhecimento)' e 'LGBT' não retornou nenhum resultado. A base LISA não identificou nenhum artigo referente à temática pesquisada. Esses dados demonstram uma lacuna existente no âmbito acadêmico e a necessidade de se realizar pesquisas que envolvam a questão dos gêneros no processo de GC.

Neste sentido, ressalta-se que as organizações contemporâneas podem ser consideradas ambientes micro societais, uma amostra e uma representação cultural dos elementos que constituem a sociedade como um todo. Além disso, o mundo é formado por inúmeras organizações, então, não há como falar de diversidade cultural sem apontar suas características dentro dos ambientes organizacionais.

O ambiente organizacional, na contemporaneidade, caracteriza-se por mudanças que determinam novos cenários; novas bases nas relações sociais; a coexistência de mundos distintos, complexos, ambíguos e fluidos, significando rupturas, novas leituras e linguagens (ALMEIDA, 2008, p.33).

Ou seja, atualmente, devido às grandes mudanças que sofrem a sociedade, até mesmo pela globalização, e no Brasil, devido à sua formação epistemológica que já é pautada pela diversidade, as organizações naturalmente necessitam em sua base ser 
composta por diferentes culturas e mundos dentro de um ambiente só, pois é dessa maneira que podem se adaptar ao mundo que habitam seus clientes.

De acordo com Cox (1993), a diversidade cultural se divide, dentro das organizações, entre dois grupos, sendo eles: grupos de minorias e grupos de maioria. Para o autor, os primeiros são compostos por mulheres, negros, índios e pessoas que não tiveram acesso a educação durante sua trajetória de vida; enquanto que os grupos de maioria são constituídos por homens e brancos, que muito pelo contrário, tiveram acesso a melhores oportunidades educacionais e de ascensão profissional durante toda sua vida. Em termos de estrutura organizacional, para o autor, os grupos de maioria estão alocados aos cargos mais elevados de uma organização, e os grupos de minorias, em verdade, lutam para serem inseridos sem preconceitos nessas organizações. No entanto...

[...] a competitividade capitalista avança com o desenvolvimento de novas tecnologias; por outros, com a reestruturação, flexibilização dos padrões de emprego e rotina de trabalho, e desconcentração do espaço físico produtivo, desencadeiam uma crescente redução do proletariado fabril, estável, desenvolvido na vigência do binômio taylorismo/fordismo. Resulta daí um enorme incremento dos excluídos e do 'subproletariado' fabril. O resultado é a criação de um setor, frequentemente denominado de trabalho precarizado, composto pelos 'terceirizados', subcontratados, part-time, entre tantas outras formas assemelhadas que proliferam em tantos cantos do mundo, às quais se candidatam muitas vezes os imigrantes (CARVALHO, 2010, p.29).

Assim, essas pessoas, constituintes dos grupos de minorias, por conta dos efeitos da sociedade capitalista, tendem a enfrentar ainda mais os vieses dos preconceitos, como também sofrem dificuldades para se inserirem com dignidade nas organizações. Para tanto, muitos autores defendem a necessidade de políticas de promoção da diversidade cultural e da gestão dessa diversidade no ambiente organizacional, com o intuito de despontar benefícios a essas organizações.

Cox e Blake (1991); Torres e Pérez-Nebra (2004) e Nkomo e Cox (2007) enfatizam que o estudo e a inserção da diversidade cultural nesses contextos são capazes de enfatizar os grupos de minorias, que são colocados à margem durante toda a história.

Portanto, a gestão da diversidade cultural surge para aumentar a eficácia e capacidade organizacional, atribuindo valor à diversidade dos funcionários que atuam nas organizações (KNOMO; COX, 2007). Mais especificamente, O’Mara (1994) listou as razões empresariais que levam à necessidade de gerenciar a diversidade cultural, são essas: (i) adicionar vantagem competitiva em recrutamento e retenção; (ii) melhorar a produtividade, qualidade, criatividade e satisfação dos grupos no trabalho, (iii) melhorar a qualidade do serviço ofertado ao consumidor e o marketing da empresa e (iv) reduzir a discriminação e o assédio sexual. 
Por mais, Cox e Blake (1991) reforçam ainda mais essas razões na medida em que afirmam que a gestão da diversidade cultural pode contribuir para a eficácia organizacional, pois: (i) reduz o custo com rotatividade e absenteísmo, (ii) retém funcionários criativos e flexíveis à organização, (iii) incentiva a luta contra a discriminação, (iv) aumenta a capacidade de resolução de problemas e (v) diminui a rigidez do sistema administrativo.

Dessa maneira, reflete-se que se a sociedade não busca ver a diversidade como algo positivo e sinérgico que sucede das relações e comunicação humana, é então dever das organizações incentivar esse processo, não só para benefícios nos resultados das organizações, mas também para o desenvolvimento social como um todo, amenizando os pontos negativos que a globalização e o capitalismo também trazem. Logo, assim como a GC, a gestão da diversidade cultural é uma maneira de valorizar o ser humano e suas mais profundas expressões positivas. Segundo Bouquehais (2017, p.31):

Em síntese, os estudos sugerem que além da necessidade de se atentar
para a importância que os valores de uma CO têm sobre as práticas de GC,
é importante realizar a identificação da cultura ou subcultura prevalente em
uma organização ou grupo. Disso decorre a necessidade da implementação
de ações para a criação de um clima favorável, para a implementação de
práticas de GC de sucesso nas organizações, contribuindo para a
consecução dos objetivos organizacionais e aumento da satisfação dos
colaboradores.

É relevante discutir o papel da cultura em relação à criação e difusão do conhecimento. Wilson (1997) afirma que as diferenças culturais influenciam na transferência de informações no âmbito da inovação e na maneira como os indivíduos adquirem informações. Esta é uma perspectiva que aborda a cultura não apenas quanto às origens nacionais, mas também considera o estilo de vida e a questão do gênero.

O modo de ver o mundo e produzir e usar conhecimento para trabalhar pode ser influenciado por fatores culturais. Pode-se, portanto, estender os valores culturais de Hofstede, Pedersen e Hofstede (2002), para compreender as subculturas em um país, enfocando a perspectiva de gênero. Destaca-se que os atributos masculinos ou femininos não se restringem ao sexo, podendo ser adotados indistintamente por homens ou mulheres, ou mesmo por nações inteiras. Para os autores supracitados, os termos 'feminino' e 'masculino' são metáforas para diferenciar as culturas nacionais mais competitivas e agressivas, ditas masculinas, das mais orientadas a valores humanísticos, à igualdade, ao preservar e ao cuidar, ditas femininas. É preciso compreender as particularidades e os desafios enfrentados por indivíduos das distintas culturas, para que haja uma inclusão efetiva destes na organização. Igualmente importante é aproveitar as perspectivas culturais, transformando-as em valor para a organização.

Nonaka e Takeuchi (1997) afirmam que para a criação de novos conhecimentos, questão relacionada à inovação, deve haver certa redundância na disponibilidade de 
informações, ou seja, uma variedade de informações que considerem um tema por perspectivas distintas. Para os autores são importantes as equipes multifuncionais, onde cada um traz sua visão sobre as questões, sobrepondo perspectivas que podem auxiliar numa visão holística do assunto.

Argumenta-se que, visto a importância da cultura na aquisição de informações e inovação, os membros da equipe possam explorar suas distintas perspectivas culturais para elaborarem soluções criativas e eficazes. Cada membro de cada cultura pode sofrer problemas que Ihes são peculiares, ter modos igualmente peculiares de enfrentá-los, tendo ainda uma peculiar visão do mundo.

A questão do gênero é particularmente relevante, tanto por ser uma forma de compreender os atributos de uma cultura, segundo Hofstede, Pedersen e Hofstede (2002), quanto pela evidência que tem tomado no Brasil, mediante acalorados debates. Visto que um grande contingente de mulheres e homossexuais têm contribuído para 0 desenvolvimento das organizações brasileiras, é preciso dar-lhes voz, permitindo que participem na criação do conhecimento organizacional, trazendo sua visão de mundo, contribuindo, em última instância, para construir organizações e sociedade mais igualitárias.

Para Marchand, Kettinger e Rollins (2001) um dos principais desafios das organizações é encontrar meios de formalizar o conhecimento nas mentes de seus sujeitos organizacionais para o uso presente e futuro. Neste aspecto, as ferramentas tecnológicas desempenham importante papel, não só para intensificar os fluxos de conhecimentos, como afirma Peréz-Montoro-Gutiérrez (2008), mas como um espaço de debate democrático, em que os grupos marginalizados têm oportunidade de se expressar.

Lévy (1998) idealizou a chamada ágora virtual, um ambiente no ciber espaço onde os cidadãos poderiam fazer valer sua vontade de maneira direta, sem a necessidade de recorrer a representantes. Segundo o autor, a ágora era um espaço onde os cidadãos da antiga Grécia podiam resolver diretamente os problemas da comunidade, visto que eram relativamente poucos, excluindo escravos, estrangeiros e mulheres. Ainda na perspectiva do autor, o ciber espaço poderia se tornar um meio viável de participação democracia direta, devido ao grande número de cidadãos na contemporaneidade. Acredita-se que as redes sociais e as wikis, abordadas na seção 4.1, têm o potencial para concretizar essa visão, e que elas podem ser utilizadas pela organização como um âmbito onde todos possam expor suas perspectivas culturais. De fato, já se evidencia o uso das redes sociais para o ativismo das mulheres e dos indivíduos LGBT. Essa prática necessita ser, portanto, institucionalizada. 


\section{Conclusão}

A pesquisa considerou a contribuição da diversidade cultural na GC. Não se trata especificamente da cultura organizacional, pois a contribuição desta última para a GC já é largamente discutida no âmbito acadêmico. Considerou-se, no entanto, a contribuição que os sujeitos organizacionais podem trazer ao conhecimento organizacional advinda de suas próprias perspectivas culturais pessoais. Considerando o modelo de valores culturais de Hofstede, Pedersen e Hofstede (2002), selecionou-se um atributo em especial: o gênero. Foram discutidas algumas características e desafios enfrentados pelas mulheres e indivíduos LGBT, inseridos em culturas, segundo a perspectiva apresentada por Semprini e Pelegrin (1999). Verificou-se que, embora os indivíduos dos grupos já mencionados estejam cada vez mais em evidência, os estudos que os relacionam com a GC são raros no âmbito acadêmico. Ademais, com o intuito de responder ao problema de pesquisa, considerou-se que a diversidade cultural, focando especificamente no gênero e grupos LGBT, pode ser considerada relevante como fator crítico de sucesso na GC. Isto é, sujeitos organizacionais com características distintas dentro de um ambiente organizacional pode ser fator potencial para o fomento de criação do conhecimento organizacional, no sentido em que diferentes culturas e perspectivas de vida formam diferentes tipos de conhecimento.

Discutiu-se ainda o papel imprescindível das ferramentas tecnológicas para o registro e a difusão do conhecimento. Sugeriu-se que a tecnologia, especialmente o ciber espaço, pode ajudar a criar um ambiente democrático para a expressão das diferentes perspectivas culturais, trazendo o ativismo que já acontece nas redes sociais para o âmbito da organização.

Assim, espera-se que os estudos considerando a $G C$ e as questões de gênero se proliferem, visando atender a essa demanda. Como trabalhos futuros, sugere-se efetuar um estudo da GC considerando os demais valores culturais mencionados por Hofstede, Pedersen e Hofstede (2002) além do gênero: a identidade, a hierarquia, a verdade e a virtude.

\section{AGRADECIMENTOS}

À Coordenação de Aperfeiçoamento de Pessoal de Nível Superior (CAPES) e ao Conselho Nacional de Desenvolvimento Científico e Tecnológico (CNPq). 


\section{REFERÊNCIAS}

ALMEIDA, A.L. de C. A construção de sentido sobre "quem somos" e "como somos" percebidos. In: MARCHIORI, M (Org.). Faces da cultura e da comunicação organizacional. 2.ed. São Paulo: Editora Difusão, 2008.

ATKINSON, E. Six ways to tackle the gender pay gap. BBC News. Disponível em: <http://www.bbc.com/news/uk-37164297>. Acesso em: 02 nov. 2017.

BRAQUEHAIS, A.P.; WILBERT, J.K.W.; MORESI, E.A.D.; DANDOLINI, G.A. O papel da cultura organizacional na gestão do conhecimento: revisão de literatura de 2009 a 2015.

Perspectivas em Gestão \& Conhecimento, João Pessoa, v.7, n.esp, p.80-93, 2017.

CARVALHO, E.J.G. Educação e diversidade cultural. In: CARVALHO, E.J.G; FAUSTINO, R.C. (Org.). Educação e diversidade cultural. Maringá: Eduem, 2010, p.17-54.

COX Jr, T. Cultural diversity in organizations: theory, research e practice. San Francisco: Berrett Koehler, 1993.

COX JR., BLAKE, S. Managing diversity: implications for organizational competitiveness. Academy of Management Executive, v.5, n.3, p.45-57, 1991.

DAVI, E. H. D. Resistências e recusas: a cultura LGBT contrapondo-se a homofobia em Uberlândia. Caderno Espaço Feminino. Uberlândia, v. 24, n. 1, p. 141-161, Jan./Jun. 2011. FURLANETTO, A.; OLIVEIRA, M. Fatores estratégicos associados às práticas de gestão do conhecimento. Análise, Porto Alegre, v.19, n.1, p.99-123, jan./jun. 2008.

GIL, A.C. Como elaborar projetos de pesquisa. 4.ed. São Paulo: Atlas, 2009.

HOFSTEDE, G.J; PEDERSEN, P.B; HOFSTEDE, G. Exploring culture: exercises, stories and synthetic cultures. Boston: Intercultural Press, 2002.

IRVINE, J. M. A place in the rainbow: theorizing lesbian and gay culture. In: NARDI, P. M.; SCHNEIDER, B. E. (Org). Social perspectives in lesbian and gay studies: a reading. New York: Routledge, 1998. p.573- 588.

JANUZZI, C.S.C.; FALSARELLA, O.M.; SUGAHARA, C.R. Gestão do conhecimento: um estudo de modelos e sua relação com a inovação nas organizações. Perspectivas em Ciência da Informação, v.21, n.2, p.97-118, jan./mar.2016.

LÉVY, P. A Inteligência coletiva: por uma antropologia do ciberespaço. São Paulo: Edições Loyola, 1998.

LIPS, Hilary M. The Gender Pay Gap: Challenging the Rationalizations. Perceived Equity, Discrimination, and the Limits of Human Capital Models. Sex Roles (2013) 68: p.169-185.

MARCHAND, D.A; KETTINGER, W.J; ROLLINS, J.D. Information orientation: the link to business performance.Oxford University Press, 2001. 
MARCONI, M.A; LAKATOS, E.M. Fundamentos de Metodologia Científica. Atlas: São Paulo, 2017.

MENEZES, K.C; JOHANN, J; VALENTIM, P.P; SCOTT, P. Gestão do Conhecimento nas Organizações: uma aprendizagem em rede colaborativa. Perspectivas em Gestão \& Conhecimento, João Pessoa, v. 7, Número Especial, p. 145-159, mar. 2017.

MOLINA, L. G. VALENTIM, M. L. P. Memória organizacional como forma de preservação do conhecimento. Perspectivas em Gestão \& Conhecimento, João Pessoa, v. 5, n. 2, p. 147-169, jul./dez. 2015.

NKOMO, S. M; COX Jr, T. Diversidade e identidade nas organizações. In: CLEGG, S. R; HARDY, C; NORD, W. R (Orgs.). Handbook de Estudos Organizacionais: Modelos de análise e novas questões em estudos organizacionais (pp. 332-358). São Paulo: Atlas, 2007.

NONAKA, I; TAKEUCHI, H. Criação de conhecimento na empresa: como as empresas japonesas geram a dinâmica da inovação. Rio de Janeiro: Elsevier, 1997.

O'MARA, J. Managing diversity. In: TRACEY, W.R. Human Resources Management e Development Handbook. New York: AMACON, 1994.

OLIVEIRA, R.R.; OLIVEIRA, R.R.; LIMA, J.B. Reflexão sobre a relação entre a mudança de cultura organizacional e a gestão do conhecimento. Perspectivas em Gestão \& Conhecimento, João Pessoa, v.6, n.1, p.19-35, jan./jun. 2016.

PÉREZ-MONTORO-GUTIÉRREZ, M. Gestión del conocimiento en las organizaciones: fundamentos, metodología y praxis. Gijón: Trea, 2008.

POMBO, O. Interdisciplinaridade: ambições e limites. Lisboa: Antropos, 2004.

SANTOS, V.C.B.; YAFUSHUI, C.A.P. A competência em Informação utilizada pelas organizações no contexto informacional e do conhecimento. In: IV Seminário HispânicoBrasileiro de Pesquisa em Informação, 2015, Marília. SEMPRINI, A; PELEGRIN, L. Multiculturalismo. Bauru: EDUSC, 1999.

SIQUEIRA, V.V.S.B. Comunidade LGBT: um levantamento das estratégias de interação entre empresas e comunidade LGBT. Brasília, 2015. TCC (Graduação em Administração) Universidade de Brasília.

SOUZA, L.P.P.; FERRARI, F.C. Estudo da aplicação de aspectos da Gestão do Conhecimento no Desenvolvimento Ágil de Software. Revista T.I.S, São Carlos, v.4, n.1, p.59-67, jan.;abr. 2015.

TORRES, C.V.; PEREZ-NEBRA, A.R. Diversidade cultural no contexto organizacional. In: ZANELLI, J.C.; BORGES-ANDRADE, J.E.; BASTOS, A.V.B (Org.). Psicologia, Organizações e Trabalho no Brasil. Porto Alegre: Artmed, 2004. 